\title{
IN MEMORIAN: REFLEXÕES SOBRE MEMÓRIA, SUICÍDIO E GÊNERO
}

\author{
IN MEMORIAN: REFLECTIONS ON MEMORY, \\ SUICIDE AND GENDER
}

Dulceli de Lourdes Tonet Estacheski ${ }^{1}$

RESUMO: Este artigo reflete sobre a morte e seus lugares de memória e sobre o suicídio cercado de tabus e silenciamentos. Discorre sobre um conjunto de práticas comuns a respeito do que lembrar e do que esquecer para determinada sociedade, sem deixar de lado a problematização sobre toda sociedade ter também memórias subterrâneas e memórias proibidas. Narrativas de testemunhas de inquéritos policiais sobre suicídios do final do século XIX e início do século XX em Castro/PR são utilizadas como exemplos de 'não lembrar', 'não dizer', para não constituir uma memória que justifique um ato suicida. Nesses documentos policiais se destacam também distinçôes sociais de gênero que serão problematizadas.

Palavras-Chaves: Memória; Suicídios; Silêncio.

ABSTRACT: This article reflects on death, its places of memory and about suicide, surrounded by taboos and silencing. It discusses a set of common practices regarding what to remember, and what to forget, for a certain society, without neglecting the problematization of every society also having its subterranean memories and forbidden memories. Narratives of witnesses to police inquiries into suicides of the late nineteenth and early twentieth century's in Castro / PR are used as examples of 'not remembering', 'not saying', so as not constitute a memory with like a justifying a suicidal act. In these police documents, there are also social gender distinctions that will be problematized.

Keywords: Memory; Suicides; Silence.

\section{INTRODUÇÃO}

Esquecimentos e lembranças fazem parte das reflexóes sobre a memória. Sua especificidade seletiva já foi amplamente abordada. Eventos felizes são guardados na memória e também nos lugares de memória (NORA, 1993). Álbuns de fotografias guardam memórias, fazem lembrar os nascimentos, festas, encontros, fases boas da vida das pessoas. Monumentos em praças públicas fazem lembrar os eventos e as celebridades. O cemitério, espaço que marca um dia de dor, de perda, transforma-se em lugar de memória, pois ao ser revisitado em outro momento, que náo o do dia do enterro, passa a ser um espaço

1 Doutoranda em História pela Universidade Federal de Santa Catarina. E-mail: dulce_tonet@yahoo.com.br 
de lembranças. Ilton Cesar Martins (2008, p. 77) o define como um "espaço de memória social e cultural, capaz de suprir lacunas existentes pela falta de museus, casas de memória e centros de preservação em cidades pequenas." O dia de finados, feriado nacional, é dia de rememorar com flores, velas e celebraçóes as pessoas que partiram

Cabe ressaltar a assertiva de Esteváo de Rezende Martins ao refletir sobre estes espaços ou objetos que fazem lembrar:

O documento ou o monumento não "se lembra", mas lembra a mim, a nós, tal ou qual ocorrência. Ankersmit propóe colocar esses dois sentidos em uma fórmula paradoxal, ao dizer que esses "fatores externos" nos lembram algo sem ser responsáveis pela existência dessa lembrança em nós.” (MARTINS, 2008, p. 22)

Constituímos lugares de memória, como o cemitério, ou momentos de memória, como as datas comemorativas, para lembrar experiências vividas, por nós ou pela comunidade a que pertencemos porque a memória corrobora com uma ideia de identificação. Não por acaso a doença de Alzheimer é tão temida, perder a memória, é perder a capacidade de lembrar-se de quem somos, já que as experiências nos constituem. Halbwachs (1990) na década de 1930 cunhou o conceito de memória coletiva e é até hoje apresentado como um dos mais importantes pensadores sobre o tema. Para ele a memória é coletiva, pois

[...] Nossas lembranças permanecem coletivas, e elas nos são lembradas pelos outros, mesmo que se trate de acontecimentos nos quais só nós estivemos envolvidos, e com objetos que só nós vimos. É porque, em realidade, nunca estamos sós. Não é necessário que outros homens estejam lá, que se distingam de nós: porque temos sempre conosco e em nós uma quantidade de pessoas que náo se confundem. (HALBWACHS, 1990, p. 26)

Carregamos em nós experiências da coletividade, além daquilo que nos é particular e nos faz contribuir com o coletivo. Somos constituídos pela cultura histórica da sociedade em que estamos inseridos. Para Halbwachs (1990) não se trata sempre de uma forma de dominação, no sentido de uma memória oficial sendo imposta, mas também de coesão em relação a uma "comunidade afetiva" da qual se quer fazer parte.

Há, evidentemente, lembranças que são traumáticas e algumas situaçóes da vida que preferimos esquecer. Coisas sobre as quais não se quer falar, pois a lembrança causa algum tipo de sentimento negativo, dor, vergonha, culpa. Silenciar sobre certas coisas pode ajudar algumas pessoas a prosseguir. Memórias podem ser silenciadas também quando contestam a coesão nacional, como bem argumentou Michael Pollak (1989), em seu texto 'Memória, esquecimento, silêncio', em que traz à tona a discussão sobre o caráter problemático deste pensamento de Halbwachs, que harmoniza a ideia de memória coletiva, apontando para estudos recentes que privilegiam o que Pollak (1989) chama de memórias subterrâneas, analisando excluídos, marginalizados, minorias, que se opóem a uma memória oficial ou nacional. Para o autor tais pesquisas denotam a perspectiva destruidora ou uniformizadora da memória coletiva, que em momentos de crise, entra em disputa com as memórias subterrâneas, aquelas desprezadas por não colaborarem com a coesão desejada. 
Pollak (1989, p. 3) apresenta, entáo, a ideia de uma memória clandestina ou proibida que sobrevive, como lembranças traumatizantes, "que esperam o momento propicio para serem expressas". Tais memórias pertencem a grupos minoritários inseridos em uma sociedade pretensamente englobante. $\mathrm{O}$ autor enfatiza as lembranças proibidas, indizíveis e vergonhosas que acabam sobrevivendo apenas em estruturas informais de comunicação, em círculos de amizades e na família.

Por conseguinte, existem lembranças de uns e de outros, zonas de sombra, silêncios, 'não ditos'. As fronteiras desses silêncios e 'não ditos' com o esquecimento definitivo e o reprimido inconsciente não são evidentemente estanques e estão em perpétuo deslocamento. Essa tipologia de discursos, de silêncios, e também de alusóes e metáforas, é moldada pela angústia de não encontrar uma escuta, de ser punido por aquilo que se diz, ou, ao menos, de se expor a mal-entendidos. (POLLAK, 1989, p. 6)

A morte de uma pessoa querida é um momento de dor. Traumatizante quando se trata de um acidente ou de uma doença terminal que acomete uma pessoa jovem, esperada quando se trata de pessoas muito idosas, mas de qualquer forma, triste e sempre acompanhada por ritos de memória. O enterro em um campo considerado santo, o cemitério, a celebração de despedida, o velório com as conversas que produzem lembranças sobre a pessoa que morreu, as celebraçóes posteriores, como a missa de sétimo dia para os católicos, as visitas ao túmulo nos dias de finados. Tudo faz lembrar, e na maioria das vezes, do que foi positivo. As mágoas, as controvérsias, parecem perder a importância e não fazer mais sentido. A ausência da pessoa significa não haver mais conflito possível, então é preferível lembrar daquilo que foi positivo apenas.

A construção do túmulo como monumento in memorian, a lápide e os dizeres de saudade são tão significativas quanto o ritual da memória que acompanha a cremação, seja quando as cinzas são guardadas em um recipiente que ficará próximo à família da pessoa falecida ou quando são espalhadas em um lugar que foi significativo para essa pessoa, local que se constituirá em lugar de memória, para os vivos, em relação a quem morreu.

A importância do respeito à memória após a morte é algo tão significativo que nas Ordenaçôes Filipinas, antigo código de leis português também vigente no Brasil no período colonial, havia não apenas a pena de morte, mas também a pena de morte da memória do sujeito condenado. Lara (1999, p. 22) ao explicar o que se chamava de "mil mortes" explicita que a pessoa condenada a "morrer por isso", não teria a morte de seu corpo como puniçáo, e sim sofreria uma morte civil, perdendo seus bens ou grau social e, por vezes, sendo degredada. A condenação a "morrer por isso morte natural" é que designava a morte do corpo, que se dava por meio de envenenamento, açoites com instrumentos de ferro, pessoas poderiam ser condenadas a morrer pelo fogo ou pela forca. E havia variaçóes para essa punição que deixavam a punição mais grave, "podia-se ter ainda a morte cruel (com suplícios) e a atroz (a seguida de confisco dos bens, proscrição da memória, queima de cadáver etc.)" (LARA, 1999, p. 23). Morrer o corpo e morrer a memória seria a condenaçáo extrema. Perdia-se o direito de estar nesse mundo até mesmo na lembrança de quem nele fica.

Destoando de todo esse culto à memória de pessoas falecidas, está a relação que se estabelece com os suicidas, que se inserem em outro contexto. A morte cercada de tabus 
dos que decidem colocar fim à própria vida já chegou inclusive a lhes negar os lugares de memória em algumas comunidades religiosas. Muelas e Mangalo (2007), psiquiatras espanhóis, traçam um interessante panorama sobre como ao longo da história, diferentes grupos sociais consideraram o suicídio baseados em seus princípios filosóficos, religiosos, intelectuais sociais ou econômicos. Iniciam afirmando que na antiguidade havia maior aceitação do suicídio, mesmo que ele tenha sido entendido de diferentes modos nas diferentes culturas. Cleópatra deixou-se picar por uma serpente que lhe causou a morte, os maias veneravam Ixtab, deusa do suicídio que era entendido como aceitável se fosse para salvar uma pessoa da vergonha e ou da desgraça.

$\mathrm{Na}$ Roma antiga, Sêneca justificava o direito à morte voluntária, que podia ser algo honroso para políticos ou intelectuais. Porém, entendia que tal direito não poderia ser dado a escravos cuja vida era economicamente importante àqueles que deles usufruíam (MUELAS e MANGALO, 2007). Se de um lado princípios filosóficos em relação ao direito à vida e à morte são apresentados, de outro, o pensamento econômico o supera. $\mathrm{O}$ direito à morte náo era para todos. A reflexão primeira considerava que a pessoa que entendesse sua vida como insuportável ou indigna tinha direito a acabar com ela, mas se fosse um escravo, que em tal condição provavelmente sofresse com tais pensamentos sobre a situação em que se encontrava e poderia desejar a morte, tal direito lhe era negado, visto que seu trabalho e os produtos por ele gerados eram mais importantes do que seu sentimento em relação à própria vida.

$\mathrm{Na}$ Idade Média o suicídio passou a ser considerado um tabu e o ato passou a receber condenaçóes sociais e religiosas. A Igreja passou a contribuir para a incriminação do suicídio, mesmo que isso tenha se dado de forma contraditória, pois a igreja primitiva incitava o suicídio pelo martírio, deixar-se matar para entrar no reino dos céus era louvável. Porém, a partir do pensamento de Santo Agostinho o suicídio passou a ser encarado como possessão demoníaca e a Igreja passou a afirmar que somente Deus tem direito a tirar a vida, já que seria ele o seu autor. Para a Igreja que antes era subversiva, a saída desse mundo pelo martírio era um ato de resistência, quando seu poder passou a transcender o mundo espiritual, ela passou a pregar o domínio também desse mundo e pelo Concílio de Toledo (693 d. C.) os autores de tentativas de suicídio passaram a ser condenados à excomunháo. Pelo exemplo de Judas que na tradiçáo cristá, traiu Cristo e se enforcou, o ato suicida passou a ser percebido como traição e covardia e assim, suicidas náo podiam mais ser enterrados, nos cemitérios, em terras cristãs. (ANGERAMI, 1989; MUELAS E MANGALO, 2007). E isso é significativo pela perspectiva de que sendo o cemitério um lugar de memória, a negação de ocupar esse espaço relegava a pessoa suicida ao esquecimento, ela perdia o direito de ser lembrada. Náo era considerada digna de estar entre os fiéis ali sepultados e de, como eles, receber as celebraçóes in memorian por sua alma.

Ao abordarem a Idade Moderna, Muelas e Mangalo (2007) salientam que pensamentos divergentes surgem com maior ênfase. Citam Montaigne que afirmava que a morte era viável quando a vida se tornasse um mal, a não ser que a vida sofrida fosse uma forma de sacrifício por outrem. Hume questionou o argumento posto por Santo Agostinho de que náo era permitido tirar a própria vida, pois ela pertencia a Deus e não à pessoa. 
Para o filósofo, a máxima deveria então valer para o caso contrário, por essa lógica não seriam também permitidas por Deus tentativas de salvar vidas, já que isso também seria uma intervenção humana em algo que só caberia a Deus decidir. Kant e Nietzsche eram contrários ao ato suicida. Para o primeiro o suicídio representava a perda da dignidade humana e para o segundo, o sofrimento devia ser aceito como parte da vida. Assim, o suicídio é pensado pelos autores a partir dos intelectuais e seus posicionamentos.

Fato é que o pensamento cristão em relação ao suicídio se perpetuou por longo tempo. O catecismo da Igreja Católica cuja elaboraçáo foi assumida pelo Papa João Paulo II, tarefa concluída em 1992, afirma que a vida é dom divino e deve ser preservada pelas pessoas. No parágrafo 2280 consta: "Nós somos administradores e não proprietários da vida que Deus nos confiou; não podemos dispor dela." E no parágrafo seguinte salienta que o suicídio é uma ofensa ao próximo porque "quebra injustamente os laços de solidariedade com as sociedades familiar, nacional e humana, em relação às quais temos obrigaçóes a cumprir." (CATECISMO DA IGREJA CATÓLICA, 1997). A mudança significativa que tal documento trouxe é a ideia de que a condenação do suicida pode náo ser eterna, dependendo do arrependimento do sujeito e da misericórdia divina e com isso, a Igreja passou a permitir a oração pelas pessoas que atentaram contra a própria vida. Isso significa que celebraçóes e sepultamentos passaram a ser permitidas.

Mesmo com as mudanças, o ato de tirar a própria vida é encarado pela nossa sociedade ocidental como algo tão extremo que é complicado falar sobre o tema. Há a controversa teoria de que noticiar os casos de suicídio se torna um estímulo para que outros potenciais suicidas cometam o ato, como esclarece Angerami (1986, p. 31) ao afirmar que "alguns teóricos afirmam que o suicídio é uma epidemia contagiosa que se alastra no seio da sociedade quando divulgado". E é preciso considerar os sentimentos confusos, entre dor, culpa e vergonha, das pessoas que eram próximas ao suicida e preferem, portanto, silenciar sobre o assunto.

O pensamento religioso cristáo, mesmo que a Igreja tenha mudado sua postura frente às pessoas que colocam fim à própria vida, passando a rezar por elas, ainda tem a questáo do valor da vida e devoção da mesma a Deus. O sofrimento, para os cristãos, deve ser entendido como algo a ser encarado para a redençáo futura, na outra vida. Sair dele pelo suicídio é percebido como fraqueza e falta de fé, e é algo que não pode ser justificado, mesmo que seja entendido ou perdoado.

No arquivo público da cidade de Castro/PR, Casa da Cultura Emília Erichsen, há um número significativo de inquéritos policiais que investigaram suicídios. Tais documentos ajudam a aprofundar as reflexóes aqui apresentadas, pois as narrativas neles presentes dão conta de percepçóes de uma determinada comunidade sobre o tema. Encontrei 73 inquéritos referentes ao período de 1890 a 1940 e um processo crime por indução de uma pessoa ao suicídio. ${ }^{2}$ Esses 74 documentos não serão analisados em sua totalidade nesse artigo, apenas alguns casos serão utilizados, mas estes dados são apresentados, para deixar

2 Esse processo refere-se à morte de um senhor que segundo relatos das testemunhas estava há muito tempo doente e queria morrer. Inésia foi acusada de ajudá-lo nessa ação. (Processo crime. Induzir ao suicídio. Inésia Maria Gonçalves. Caixa: 1908. Casa da Cultura Emília Erichsen, doravante designada pela sigla CCEE. Castro/PR). 
claro que é significativa a média de 1,48 suicídios por ano em uma cidade de cerca de quinze mil habitantes no período estudado.

Duas explicaçóes são percebidas aqui como necessárias, a primeira se refere à cidade de Castro/PR, para situar o leitor e a leitora no contexto em que os suicídios ocorreram e a segunda tem relação com as fontes de pesquisa, esclarecendo como documentos policiais podem ser utilizados para uma análise que leva em conta a questão da memória.

Sobre a primeira questão, Castro é uma cidade interiorana do Estado do Paraná que se constituiu a partir do tropeirismo. Lazier (2003) ressalta que a atividade tropeira foi responsável por integrar o Paraná economicamente ao restante do país e por conferir uma dinâmica específica à ocupação territorial do estado. As viagens dos tropeiros com o gado, que saíam do Rio Grande do Sul e se dirigiam a Sáo Paulo exigiam paradas para pernoite, descanso e alimentação das pessoas e dos animais. Nos pontos de parada foram surgindo pequenos povoados com armazéns, ferrarias e outros estabelecimentos de pessoas ligadas ao trabalho com o gado (WACHOWICZ, 1968). Alguns povoados se tornaram cidades mais tarde, é o caso de Castro.

Como outras cidades pequenas e interioranas, Castro tinha, no período estipulado por essa pesquisa (1890-1940), a religiosidade como uma das características da população. Na cronologia da cidade há várias menções a fundação de Igrejas e capelas, como a católica de Santa Clara em 1890, a Luterana em 1899 e o templo presbiteriano em 1911. Destaca-se a visita do bispo em 1897, a fundação do Jornal 'A Aurora do Evangelho' em 1896 e do Jornal 'O Testemunho' da igreja presbiteriana em 1928. A fundação de uma escola católica em 1900 e a da casa paroquial luterana em 1902 também são mencionadas, assim como a passagem do monge João Maria na cidade foi registrada em 1906 (DINIZ et all, 2003). Esses dados são importantes, pois revelam que a comunidade local vivenciava práticas relacionadas à fé cristã e ao pensarmos na reação das pessoas diante de casos de suicídio, não podemos perder isso de vista.

Sobre a segunda questão, as fontes de pesquisa, os documentos policiais não são, em si, lugares de memória, mas como a investigação policial, ao questionar as testemunhas, as fez lembrar e narrar algo sobre o suicida ao tentar encontrar algo que elucidasse os fatos, ficaram nesses inquéritos, os registros de memórias das pessoas próximas àquelas cuja morte era investigada. Uma das mais interessantes narrativas sobre o uso de arquivos do judiciário como fonte para a pesquisa histórica foi realizada por Arlette Farge em sua obra 'O sabor do arquivo' (2009). Embora ela trate mais especificamente dos documentos que encontrou para sua pesquisa referente ao século XVIII na França, vários elementos que ela destaca são pertinentes para nossa reflexão. Os inquéritos policiais são documentos que foram constituídos para um uso imediato, para atender as necessidades do momento em que foram criados, que era registrar as informaçóes policiais sobre determinada investigação. Após esse uso, são arquivados e passam a ter o que Farge (2009) chama de uso diferido, tornando-se testemunhos do passado e sendo úteis para a pesquisa histórica.

Ao afirmar que os documentos judiciais "revelam o que jamais teria sido exposto não fosse a ocorrência de um fato social perturbador", Farge (2009, p. 13) ajuda a refletir sobre a 
relevância dessa fonte para o tema aqui em questão. A característica invasiva desses documentos, que exigem o falar sobre uma situação limite e disso fazem registro, possibilita a análise das memórias sobre as pessoas suicidas que talvez não fossem conseguidas de outra maneira, já que a família, a comunidade, evitava falar sobre um acontecimento tão trágico que se constituiu em um tabu, como já mencionado.

Em muitos inquéritos, há testemunhas que preferem silenciar em relação a possíveis motivos que podem ter levado a pessoa ao suicídio. Uma resposta muito comum é: não havia motivo algum. A sociedade ocidental cristã que não admite que uma pessoa tenha o direito de colocar fim a própria vida, pois esta em sua crença pertence a Deus, prefere não lembrar acontecimentos que justificariam tal ato, pois é algo que não pode ser justificado, tornando-se assim uma memória proibida.

Em 1900, Joaquim foi encontrado morto, enforcado em um pessegueiro que ficava em sua propriedade. Quando foi interrogada pela polícia, sua esposa Maria afirmou que "que vivia em boa paz em companhia do finado" e que este "nunca lhe agravou em nada". A memória aqui evocada é de um bom relacionamento entre o casal, com uma interessante alusão ao fato do marido não ter sido violento. Não é possível saber o que desencadeou uma lembrança tão específica no momento do interrogatório, se foi a memória afetiva de um casamento tranquilo, se foi o medo de que alguma dúvida em relação à harmonia na relação levantasse suspeitas sobre a morte de Joaquim ou simplesmente a prática de respeito à memória da pessoa falecida que faz recordar apenas os pontos positivos da vida, deixando os conflitos no passado.

A filha de Joaquim, em seu interrogatório, disse que "não havia mottivo algum nem com gente da caza do mesmo nem com vizinhos", salientando também a característica amigável do pai, e reforça afirmando que "seu pai náo tinha mottivo algum [...] era um homem bem quisto". O testemunho foi corroborado pela narrativa de um lavrador que morava na comunidade e afirmou também que não havia nada que justificasse e "o mesmo era homem bem quisto no bairro". ${ }^{3}$ As pessoas procuram ressaltar a falta de motivo para Joaquim ter colocado fim à própria vida na mesma medida em que tentam deixar claro que ele era um sujeito querido pela comunidade local. Por um lado, náo se justifica a morte voluntária e o que poderia ser a razão de tal desespero torna-se lembrança silenciada, por outro a memória evocada em relação à pessoa falecida é positiva.

Hubaldo também se enforcou em uma árvore em $1900^{4}$ e as testemunhas disseram que não havia motivo. Em outro inquérito, as oito pessoas que foram ouvidas pela polícia na investigação sobre o suicídio de Saturnino, ${ }^{5}$ que também foi encontrado enforcado em 1904, declararam que ninguém sabia a razão do fato. Há outros exemplos nos inquéritos encontrados no arquivo que trazem esse mesmo tipo de relato, mas estes aqui apontados

3 Inquérito policial. Suicídio. Joaquim de Paula Bueno. Caixa: 1900. CCEE. Castro/PR. Optamos por preservar a grafia encontrada nos documentos.

4 Inquérito policial. Suicídio. Hubaldo Prestes Carneiro. Caixa: 1900. CCEE. Castro/PR.

5 Inquérito policial. Suicídio. Saturnino Martins de Oliveira. Caixa: 1904. CCEE. Castro/PR. 
já são suficientes para o entendimento da situação difícil em que se encontravam esses sujeitos. As testemunhas eram levadas a lembrar de algo que não queriam a respeito de uma pessoa próxima, familiar ou não, que havia morrido de uma forma não esperada e trágica. Dificilmente essas pessoas da família ou da vizinhança náo saberiam o que atormentava o sujeito que decidiu colocar fim à vida. Porém declarar isso em testemunho poderia soar como um entendimento ou uma justificativa do ato. Para a comunidade cristá da cidade interiorana, poderia parecer mais coerente negar lembranças de fatos difíceis, para que nenhum deles parecesse causar tanta dor que justificasse o suicídio. Na concepção cristá que a comunidade apresentava, o sofrimento devia apenas fazer parte da vida e não ser razão para colocar fim a ela.

Olívia, filha adotiva de um lavrador chamado Emílio, saiu de casa para ir ao dentista às dezesseis horas do dia 20 de março de 1923. O empregado da família que morava próximo, afirmou que ela regressou por volta das dezoito horas. Ele a viu passar por sua casa que era próxima à da família da jovem, e percebeu que ao invés de dirigir-se à casa dela, Olívia seguiu rumo ao cemitério. O mesmo disse que achou e comentou com sua esposa que "Olivia ia cumprir alguma promessa". Uma hora mais tarde o irmão de Olívia veio perguntar por ela e foram juntos procurá-la no cemitério e ao redor dele, nas matas. $\mathrm{O}$ corpo de Olívia só foi encontrado na manhá do dia seguinte. Ela atirou-se no rio e morreu afogada, ${ }^{6} \mathrm{e}$ todas as pessoas interrogadas disseram não saber a razáo. $\mathrm{O}$ empregado que era também vizinho apenas afirmou que Olívia "era bem tratada e no dia que desapareceu mostrava-se alegre e satisfeita". Outra empregada da casa relatou que a jovem era "sempre alegre e satisfeita". A terceira testemunha, outra vizinha, disse que "Olivia era bem tratada pelos de casa e não mostrava achar-se desgostoza de alguma couza." Verifica-se que assim como foi importante para a filha e o amigo de Joaquim, do primeiro inquérito por suicídio aqui analisado, declarar que ele era um homem bem quisto pela comunidade, foi importante para o vizinho e a vizinha de Olívia destacar que ela era bem tratada pela família.

Essas memórias são significativas para pensar as relaçóes de gênero ${ }^{7}$ que se estabeleciam na vida da comunidade e também na constituição das memórias sobre as pessoas falecidas. Na sociedade de entáo, o homem devia ter o reconhecimento das pessoas, a jovem precisava da proteção da família e por ser adotiva, devia ficar claro que era bem tratada por todas as pessoas. A memória do homem, Joaquim, é evocada para ressaltar sua figura positiva perante a comunidade, enquanto os fatores negativos que levaram ao suicídio são silenciados. A memória da jovem fica em segundo plano, ela é apontada como uma pessoa alegre e satisfeita, mas o destaque é dado para o pai adotivo, Emílio, e sua família, reforçando que sempre a trataram bem. A postura positiva aqui é direcionada à família, os sentimentos da jovem, de regozijo e satisfação, são resultado das 'pessoas boas' que a acolheram e a tratavam bem.

6 Inquérito policial. Suicídio. Olívia da Silva. Caixa: 1923. CCEE. Castro/PR.

7 Gênero é pensado aqui pela perspectiva apresentada por Joan Scott (1995, p. 14) que define a categoria como "um primeiro modo de dar significado às relaçóes de poder”. 
No final do século XIX e início do século XX, período em que tais eventos se passaram, as determinaçóes sociais de gênero conferiam um sentido muito diferente para a honra de homens e mulheres. Eles eram considerados honrados e honestos se fossem trabalhadores, se cumprissem com seus compromissos financeiros, sustentassem a família e mantivessem a palavra dada, como bem argumenta Machado em sua análise de um modelo de masculinidade em Desterro/SC no século XIX (2001). Essas práticas faziam com que os homens fossem reconhecidos positivamente pela comunidade e são essas memórias que afloram após a morte dos mesmos. As mulheres, por sua vez, tinham sua honestidade medida pela postura recatada e submissa. Caufield (2000) argumenta que as mulheres eram consideradas honestas se fossem virgens quando solteiras, fiéis quando casadas e castas ao se tornarem viúvas. Honestidade relacionada à conduta sexual regrada e à relação que tinham com os homens que eram seus tutores, pais ou maridos. Quando uma jovem perdia a virgindade antes do casamento, por exemplo, gerava um problema, pois não agravava apenas a sua honra, mas a de sua família, principalmente do pai, já que isso representava desobediência, insubmissão e, portanto, maculava a autoridade do homem em relação à sua família.

Olívia tirou a própria vida. Pessoas foram chamadas a falar sobre ela em uma tentativa da polícia de elucidar os fatos e o que fica registrado é a preocupação com a preservação da dignidade da família da jovem. Ninguém quis recordar de algo que pudesse causar tristeza a ela, ninguém quis dar a entender que o senhor Emílio, pai adotivo, não fosse um bom pai. Inclusive o fato de a jovem ter sido adotada é registrado na narrativa das testemunhas, sinal da benevolência da família que a acolhe. Se ela era bem tratada por essa família, nada deveria ter levado Olívia a buscar a morte. Era injustificável. Tanto que a sua memória é deixada de lado e a memória da família é exaltada. Enquanto Joaquim foi lembrado por ser bem quisto, o que era resultado de sua postura perante a comunidade, Olívia foi quase esquecida, sua família é que foi lembrada, porque era boa e a tratava bem.

Havia motivos para Joaquim, Hubaldo, Saturnino, Olívia, antigos moradores e moradora de Castro/PR, e tantas outras pessoas desistirem de viver, mas estes foram silenciados. Essas memórias foram negadas, proibidas, por uma sociedade que ao constituir outras memórias sobre essas pessoas revelaram, mesmo que não de forma intencional, as pressões sociais que configuravam posturas consideradas adequadas para homens e mulheres naquela cidade e naquele período. Trazer à tona os motivos que levaram essas pessoas ao suicídio poderia ser uma forma de colocar em cheque uma ordem social que as pessoas da pequena cidade interiorana de Castro/PR náo eram impelidas a questionar e muito menos a tentar mudar no final do século XIX e início do século XX. Isso fez com que não somente as dores e angústias das pessoas suicidas fossem esquecidas ou negligenciadas nos relatos das testemunhas, como fez com que a jovem Olívia fosse relegada a personagem secundária em sua própria história.

A morte é um tema difícil e a constituição de lugares de memória relacionados às pessoas que faleceram se configura em uma maneira encontrada pela sociedade ocidental cristã para manter presentes e vivas na lembrança as pessoas que já morreram. E se toda morte gera sentimentos difíceis de lidar, como a solidão, a saudade, a tristeza, que 
somente são apaziguados pelas lembranças boas, há um tipo de morte, a do suicida que coloca as pessoas em uma situação difícil. Sentimentos confusos afloram, a tristeza, a mágoa, a culpa, a vergonha, a incerteza. Nesses casos, a exaltaçáo da memória parece não dar conta. De um lado, lembrar parece uma forma de justificar o que ser entendido como injustificável, de outro, lembrar traz o questionamento que não encontrará resposta, o que de fato fez com que a pessoa sofresse tanto que decidiu colocar fim à própria vida? Lembrar pode também ser um encontro com a culpa, do pensar que algo poderia ter sido feito para que isso não tivesse acontecido.

Ao abordar o silenciamento da sociedade, ainda hoje, diante de casos de suicídio na introduçáo de seu livro que reflete sobre o saber médico em torno da morte voluntária, Lopes (2008) tece uma crítica a Mário Sabino que em um ensaio publicado em 1995 afirmou que o vazio e o sentimento de culpa são heranças de pais e amigos/as das pessoas suicidas e isso deveria ser suficiente para que se fizesse silêncio sobre essas mortes. Lopes, ao contrário, pensa que o tema precisa ser discutido e a sociedade precisa sentir-se responsável:

[...] É necessária outra atitude: pensar que todos nós somos, em parte, coadjuvantes de situaçóes, pressóes, cobranças, esperas e anseios que podem ser, às vezes, causas, desculpas ou até mesmo aquela última gota que falta para que pessoas ao nosso redor, ou até mesmo não tão próximo assim, desistam da vida. (LOPES, 2008, p. 21)

Não é um apelo à culpa, mas sim a necessidade de não colocar questóes importantes e que fazem pessoas sofrer e morrer debaixo do tapete, apropriando-me aqui de uma expressão popular que me parece significativa para ressaltar que esconder o que há de difícil na sociedade não faz desaparecer de fato o problema, ele pode retornar a qualquer momento. Em 'lugares para a história', Farge (2015, p. 23) afirma que trabalhar com temas como o sofrimento, a violência, na história é também querer que eles diminuam ou acabem hoje: "Explicando os dispositivos e os mecanismos de racionalidade que os fizeram nascer, o historiador pode fornecer os meios intelectuais de suprimi-los ou de evitá-los". Pesquisar sobre o suicídio, refletir sobre ele em diferentes espaços, é querer que mudanças sociais aconteçam para que pessoas náo se sintam impelidas a esse ato extremo.

A Joaquim, Hubaldo, Saturnino e Olívia, in memorian. 


\section{REFERÊNCIAS}

ANGERAMI, Valdemar Augusto. Suicídio: uma alternativa à vida, uma visão clínica-existencial. São Paulo: Traço, 1986.

CATECISMO DA IGREJA CATÓLICA. Edição Típica Latina. Vaticano: Libreria Editrice Vaticana, 1997.

CAULFIELD, Sueann. Em defesa da honra: Moralidade, Modernidade e Nação no Rio de Janeiro (1918-1940). Campinas: Editora da UNICAMP, 2000.

DINIZ, João Maria Ferraz et all. Castro Antiga: cronologia. Curitiba: Imprensa Oficial, 2003.

HALBWACHS, Maurice. A memória coletiva. São Paulo: Vértice, 1990.

FARGE, Arlette. Lugares para a História. Belo Horizonte: Autêntica, 2015.

FARGE, Arlette. O Sabor do arquivo. São Paulo: EDUSP, 2009.

LAZIER, Hermógenes. Paraná: terra de todas as gentes e de muita história. Francisco Beltrão: GRAFIT, 2003.

LOPES, Fábio Henrique. Suicídio \& Saber Médico. Rio de Janeiro: Apicuri, 2008.

MACHADO, Vanderlei. Honra e Conduta: Em busca da construção de um modelo burguês de masculinidade em Desterro (1850-1894). In: BRANCHER, Ana; AREND, Silvia Maria Fávero (orgs.). História de Santa Catarina no século XIX. Florianópolis: Editora da UFSC, 2001.

MARTINS, Estevão de Rezende. Memória e experiência vivida: a domesticação do tempo na história. Antíteses. v. 1, n. 1. Jan-jun/2008.

Disponível em: http://www.uel.br/revistas/uel/index.php/antiteses. Acessado em 27 de outubro de 2016.

MARTINS, Ilton Cesar. Cemitério municipal de União da Vitória: representaçóes de poder e fé. In: MARTINS, Ilton Cesar; GOHL, Jefferson William; GASPARI, Leni Trentin. Fragmentos de memória, trechos do Iguaçu: olhares e perspectivas de história local. União da Vitória: FAFIUV, 2008.

MUELAS, N. Vicente; MANGADO, Enriqueta Ochoa. Consideraciones sobre el suicídio: una perspectiva histórica. In: Psiquiatria.com, 11(3), 2007. Disponível em: http://www. psiquiatria.com/revistas/index.php/psiquiatriacom/article/viewFile/235/220/ Acessado em 27 de maio de 2016.

NORA, Pierre. Entre memória e história: a problemática dos lugares. Tradução de Yara Aun Khoury. Projeto História. Revista do Programa de Estudos Pós-graduados em História do Departamento de História da PUC/SP. Sáo Paulo, n. 10, dezembro/1993. 
POLLAK, Michael. Memória, esquecimento, silêncio. Estudos históricos. v. 2, n. 3, 1989. SCOTT, Joan. Gênero uma categoria útil para análise histórica. Educaçáo e realidade. Porto Alegre. v. 20. n. 2. Jul/dez, 1995.

WACHOWICZ, Ruy Christovam. História do Paraná. Curitiba: Editora dos Professores, 1968.

Artigo recebido em 12/09/2017

Artigo aprovado em 16/12/2017 